\title{
Into the cognitive constructs related to adherence to treatment in CHD outpatients: the importance of accepting the disease limitations
}

\section{I costrutti cognitivi correlati alla aderenza ai trattamenti nei pazienti ambulatoriali con CHD: I'importanza di accettare le limitazioni legate alla malattia}

\author{
Antonia Pierobon1, Anna Giardini1, Giuseppina Majani1, Simona Callegari1, \\ Francesca Lenta2, Maria Teresa La Rovere², Oreste Febo2
}

\begin{abstract}
Into the cognitive constructs related to adherence to treatment in CHD outpatients: the importance of accepting the disease limitations. A. Pierobon, A. Giardini, G. Majani, S. Callegari, F. Lenta, M.T. La Rovere, O. Febo.

Background and aims: Poor adherence to clinical prescriptions has been recognized as a major problem in management of chronic diseases. Only few studies tried to identify which factors could be considered predictive of low adherence to pharmacological and non pharmacological prescriptions in Coronary Heart Disease (CHD) patients. The aims of our observational-longitudinal study were to assess in CHD outpatients admitted to a Cardiological Day Hospital (DH): self-reported knowledge and acceptance about illness, perceived self-efficacy in disease management and emotional status, and the possible relationships among these variables.

Methods: Patients were assessed at baseline during the first days of DH and few days before discharge (follow-up) by the Adherence Schedule in Ischemic Heart Disease (ASIHD) and by the Anxiety and Depression Scale (AD). The ASIHD is a tool specifically aimed at evaluating the cognitive, relational and behavioural antecedents of adherence to treatment of patients suffering CHD. The rehabilitation programme comprised: individualized physical training, nutrition monitoring, psychological assessment and psychoeducational interventions, when indicated. Baseline and follow-up clinical data, ASHID and AD scores were analysed both considering the whole sample $(n=117)$ and the subgroup which met the clinical criteria for psychological counselling ( $n=35$, psychologically treated group). Intracorrelation and intercorrelation coefficients of the whole sample baseline data were calculated among ASIHD, AD scores and socio-demographic data.
\end{abstract}

Results: Our CHD outpatients (62.6 \pm 9.3 years) were mainly male, married and retired. They had 5,2 years of illness on the average, and only $9 \%$ of them were still smokers, whereas $62 \%$ had smoked in the past. Total and LDL cholesterol levels showed a significant reduction at follow up evaluation. Among ASIHD baseline item scores, many statistically significant intracorrelations emerged, in particular: disease limitations acceptance showed significant positive correlations with disease knowledge $(r=.34, p=.0001)$, family/friend support $(r=.27, p=.003)$, following dietary prescriptions $(r=.38, p=.0001)$, exercise $(r=.35, p=.0001)$, taking medicines punctually $(r=.35, p=.0001)$, identifying physical/psychological fatigue $(\mathrm{r}=.45, \mathrm{p}=.0001)$, monitoring clinical parameters $(r=.42, p=.0001)$, management of stressful situations $(\mathrm{r}=.26, \mathrm{p}=.006)$, and reducing stress sources $(\mathrm{r}=.34, \mathrm{p}=.0001)$. Concerning the significant intercorrelations between AD and ASIHD scores, disease acceptance showed negative correlations with anxiety and depression $(r=-.27, p=.004 ; r=-.26, p=.004$ respectively).

Conclusions: The pathway stemmed from our data enlights that in the area of cognitive and relational antecedents of adeherence, accepting the disease limitations can be considered a central issue in CHD patient's illness adjustment and prescriptions adherence. Moreover, the ASHID resulted a useful synthetic schedule of psychological/behavioural variables regarding perceived self-efficacy in disease management. This may facilitate a synergic team work on common priorities that respect the point of view of the patient and the clinical-rehabilitation purposes.

Keywords: coronary heart disease, adherence, self-efficacy, depression, anxiety.

Monaldi Arch Chest Dis 2009; 72: 130-138.

Salvatore Maugeri Foundation, IRCCS, Scientific Institute of Montescano, Montescano (PV) Italy.

1 Psychology Unit

2 Department of Cardiology.

Corresponding author: Dr.ssa Antonia Pierobon; Servizio di Psicologia; Fondazione Salvatore Maugeri, IRCCS; Istituto Scientifico di Montescano; I-27040 Montescano (PV), Italy - Tel. +39 385 247255; Fax. +39 385 61386; E-mail address: antonia.pierobon@fsm.it

\section{Introduction}

Poor adherence to treatment and medical advice has been recognized as a major problem in management of chronic diseases and has been widely stud- ied [1-4]. The WHO defined adherence as "...the extent to which a person's behaviour-taking medication, following a diet, and/or executing lifestyle changes corresponds with the agreed recommendations from a provider" [5]. Haynes and the Rating 
Report emphasize the contractual relationship between providers and patients: "...patients need to be supported, not blamed..." [6].

Improving adherence would have a more beneficial impact on health outcomes compared to improving specific treatments. A Cochrane review concluded that the full benefits of medications cannot be achieved due to poor levels of adherence; however, the current methods to improve adherence for chronic diseases are complex and not very effective [6]. In 2008, an update showed that simple interventions are relatively successful in improving short-term adherence; it was also stressed the need for applied research concerning patients' assistance to follow medication prescriptions for long-term medical disorders [7].

Concerning adherence in the area of heart disease, pioneer studies were mainly conducted on Heart Falure (HF). HF patients' adherence to medication and diet resulted to be poor: $20-58 \%$ and $22-$ $51.4 \%$ respectively [8]. In a more recent review, the lack of adherence to pharmacological and behavioural treatment was confirmed and in $20-64 \%$ of the cases it turned out to be a contributing factor for readmissions [9]. Literature data strongly encourages studies aimed at identifying and analyzing factors predisposing to non-adherence and those influencing its maintenance, mainly in chronic diseases [4].

Overall, the different variables identified as links to the risk of non-adherence in chronic patients as well as in heart failure and transplanted patients, could be grouped into four main classes: socio-anagraphic characteristics, medication regimen, psychological disorders, and cognitive factors.

In Coronary Heart Disease (CHD) much attention has been paid to adherence to pharmacological prescriptions, which is reported to be $50 \%$ and to decrease with the length of follow up [10-12]. Low adherence to evidence-based pharmacotherapy has been associated with an increased risk recurrence of cardiovascular disease or mortality $[13,14]$.

Only few studies tried to identify which factors could be considered predictive of low adherence to pharmacological therapies in CHD patients. In his review, Munger listed some variables contributing to non-adherence: age, ethnicity, gender, adverse effects, polypharmacy and cost [11]. The central role of depression in predicting medication non-adherence in medical patients emerged clearly from the well known meta-analysis by DiMatteo [15], which showed that depressed patients are 3 times more exposed to the risk of non adherence in comparison with non depressed patients (odds ratio 3.03; 95\% confidence interval). Depression turned out to be associated with medication non-adherence in outpatients with CHD [16].

Sud [17] found that physician discontinuity and adverse effects resulted to be the most frequent reasons for interrupting medication assumption, and among adherent patients the perceived need for medication was the strongest predictor of patients not dropping out. Illness perception which has proved to be an important determinant of adjustment, functional and emotional health in various chronic illnesses $[18,19]$ was confirmed important also in CHD patients, controlling for socio-demographic factors as well as CHD severity and history [20]. Interestingly, in healthy subjects change in self-efficacy - defined as the individual's belief in the possibility of achieving a particular goal - [21] resulted to be a predictor of change in smoking and nutrition behaviour [22]. Among the social-cognitive variables, self-regulation (considered as a construct partially overlapping self-efficacy) exerted the strongest effect on physical activity adherence and social support influenced physical activity as a direct precursor of self-efficacy and self-regulation [23].

Taken together, these data suggest that beliefs about the need and efficacy in controlling the disease progression might be relevant in determining medication adherence [24]. On the other hand, behavioural adherence (i.e. stop smoking, following dietary prescriptions, doing regular exercise,) seems to be more directly influenced by the patient's perceived self efficacy, in terms of reported difficulty and/or confidence in his/her ability to perform each recommendation [25].

Since similar data in CHD are lacking in recent literature, the present study aimed at assessing selfreported knowledge and acceptance about illness, perceived self-efficacy in disease management, emotional status in CHD patients admitted to the Cardiological Day Hospital (DH) of our Institution and the evaluation of possible relationships among these variables.

\section{Method}

\section{Procedure and sample selection}

From January 2004 to December 2004, 117 patients were consecutively enrolled.

The inclusion criteria were: ischemic and/or valvular heart disease with preserved left ventricular function in persons with at least 18 years. Exclusion criteria included chronic heart failure, heart transplantation, severe psychiatric comorbidities, unreliable psychological assessment (due to cognitive or sensorial impairment), refusal to be psychologically assessed, more than 3 days' interval between clinical and psychological assessment. Subjects were enrolled by a trained psychologist and were requested to fill in the questionnaires alone. They received help only if it was necessary and explicitly requested. All the patients signed an informed consent form.

Patients were assessed at baseline during the first days of $\mathrm{DH}$ and few days before discharge (follow-up). In both evaluations, a clinical and a sociodemographic schedule purposely made for the study, the Adherence Schedule in Ischemic Heart Disease (ASIHD) [25] and the Anxiety and Depression Scale (AD Scale) [26] of the Cognitive Behavioural Assessment 2.0 [27] were administered.

\section{Clinical and psychological rehabilitation}

The rehabilitation intervention aimed at reducing the risk of progression of the coronary disease, increasing the functional capacity and improving the quality of life [28], included monitoring of symptoms and pharmacological therapies, physical exercise, dietary prescriptions and behavioural counselling. The Day Hospital had a variable duration according to the intervention strategy and the type of 
patient.

Following a classical baseline assessment each patient received an individualized program of physical training (to be continued at home) and nutrition monitoring. Psychological assessment, counselling interventions, where indicated, and educational sessions related to the management of risk factors were added.

Psychological intervention was performed according to patients' emotional status (high or extremely low levels of anxiety and/or depression) and/or on the basis of ASIHD scores (4 or more items with answers "not at all/a little") suggesting the presence of dysfunctional illness perception, poor perceived social/family support, and low levels of self-efficacy in disease management. The psychological intervention performed by a cognitive behavioural psychotherapist consisted of one to five individualized sessions according both to the patients needs and to the day-hospital time schedule. It focused on the following cognitive, emotional and behavioural issues:

- modification of self-perception (patient-person) by working not only on the adjustment to behavioural limitations, but also on positive thinking about present life;

- correction of dysfunctional cognitive processes (causal attribution, inadequate expectations, etc);

- promote self-efficacy in modifying behavioural risk factors;

- legitimation of emotional reactions to the disease;

- identification and reinforcement of functional cognitive resources and coping abilities;

- reinforcement of adaptive behaviours oriented towards self-management and autonomy;

- redefinition of roles, family and social relationships as a consequence of illness.

Finally, an efficacy assessment of the intervention based on predetermined result indicators has been performed.

\section{Instruments}

\section{Adherence Schedule in Ischemic Heart Disease (ASIHD)}

The ASIHD is a tool specifically aimed at evaluating several variables connected with adherence to treatment of patients suffering ischemic heart disease [25]. It belongs to a wider group of Schedules aimed at assessing the cognitive, relational and behavioural antecedents of adherence to treatment in different diseases (chronic heart failure, asthma, chronic obstructive pulmonary disease) $[25,29]$. The ASIHD exists in two versions: baseline and follow up.

It is composed of two sections. In the first section, Cognitive Relational Antecedents are assessed by six items referring to patient's perception about his/her illness (self-reported illness knowledge and acceptance), the prescribed treatment and family/social support. The first section is identical in baseline and follow-up versions. In the second section, Selfefficacy in disease management is assessed by eight items referring to patient's opinions on his/her disease management both behavioural and cognitive- emotional. In the baseline version, patient's expectation and perceived self-efficacy on disease management are evaluated, whereas in the follow-up version referred self-efficacy on patient's actual disease management is assessed. Answers are provided on a 5-point Likert scale.

\section{Anxiety and Depression Scale}

The AD Schedule evaluates state and depressive behaviours [26]. The Anxiety Scale is the validated Italian version of the Spielberger STAI X1 [27]; it is composed of twenty items assessing on a four-point Likert scale symptoms frequency. Depression is assessed with a scale, validated both on healthy subjects and on hospitalized patients, composed by 24 items; functional, emotional and cognitive aspects on daily life are evaluated on a dichotomic scale. The AD Scale has been widely adopted in Italy, providing valid and reliable results $[30,31]$.

\section{Data analyses}

The following analyses were performed:

1. Sample characteristics and clinical data were analysed by descriptive statistics. Baseline and follow-up clinical data were compared by t-test for paired samples for the whole sample $(n=117)$ and for the subgroup which met the criteria for psychological counselling (psychologically treated group).

2. Descriptive statistics were calculated on ASIHD baseline and follow-up scores of the whole sample $(n=117)$ and of the psychologically treated group. Comparisons were performed by means of the non-parametric Wilcoxon test.

3. AD Scale raw scores were transformed in percentiles (by the comparison with normative data according to gender) (Sanavio, 1997); two clinical cut-offs were considered: $\leq 15^{\circ}$ and $\geq 85^{\circ}$. $\mathrm{AD}$ scores frequency distributions were compared to Italian normative data (Chi square test) and then baseline and follow-up percentile data were compared using t-test for paired samples.

4. As to socio-demographic data and ASHID scores, Spearman correlation coefficients on baseline data of the whole sample were calculated between ASIHD scores, age and years of illness. Moreover, baseline ASIHD scores were compared according to gender, educational level, family and work status (by means of nonparametric tests).

5. As to socio-demographic data and AD scale, Pearson correlation coefficients of the whole sample on baseline data between AD percentile scores, age and years of illness were calculated. Moreover, baseline AD percentile scores were compared according to educational level, family and work status (by means of parametric and non-parametric tests).

6. Correlations among ASIHD Cognitive Relational Antecedents scores were calculated on the whole sample. Furthermore, their correlations with Behavioural Adherence Self Efficacy, Stress Management Self Efficacy scores and AD percentile scores were performed. Finally, correlations between Behavioural Adherence Self Efficacy scores and Stress Management Self-Efficacy with $\mathrm{AD}$ scores were calculated. 
Since the study focuses on illness perception, the two items concerning treatment utility have been excluded from the analysis.

A $\mathrm{p}$ value $\leq 0.01$ was considered statistically significant. All analyses were performed with SPSS system 13 (Statistical Package for the Social Sciences, 2005).

\section{Results}

Our observational-longitudinal study recruited CHD outpatients of the same Institution mainly male with a low/medium level of education, married, retired and coming from a not highly urbanized environment. They had 5,2 years of illness on the average, and only $9 \%$ of them were still smokers, whereas $62 \%$ had smoked in the past.

1. In Table 1 and Table 2, the socio-demographic and clinical characteristics are presented in detail. The average time between baseline and follow-up assessment was $5 \pm 4$ months. According to the criteria for psychological intervention (low ASHID scores and/or extremely low or high AD scores), 35 (29.9\%) patients out of the whole sample of 117 were selected for counselling and psychoeducation. Among medical data, both in the whole sample and in the psychologically treated subgroup, total and LDL cholesterol levels showed a significant reduction at follow up evaluation.

2. Table 3 shows the ASIHD items response frequencies and percentages. In order to simplify data interpretation, the 5 point Likert responses were grouped in three sub-classifications: not at all/a little, enough, much/very much. Concerning the whole sample, no statistically significant differences emerged between baseline and follow-up data.

As to the psychologically treated subgroup $(\mathrm{n}=35)$, a statistically significant improvement in the acceptance of disease limitations and selfefficacy in following dietary prescriptions was observed (Table 4).

3. As for the AD scores, no statistically significant differences emerged with normative data and between baseline and follow-up scores for both the whole sample and the psychologically treat- ed group. As to the 117 patients, only $17.1 \%$ and $21.4 \%$ of the patients reported a score above $85^{\circ}$ percentiles in anxiety and depression respectively (AD Scale).

The statistically significant correlations on baseline data of the whole sample are listed in the fol-

Table 1. - Socio-demographic characteristics and clinical data

\begin{tabular}{|c|c|}
\hline Variables $(n=117)$ & Total or value \\
\hline Female/male $(n, \%)$ & $12: 105(10.2: 89.8)$ \\
\hline Age $($ mean \pm SD $)$ & $62.6 \pm 9.3$ \\
\hline $\begin{array}{l}\text { Family status }(n, \%) \\
\text { - Married/living together } \\
\text { - Single } \\
\text { - Widowed } \\
\text { - Separated/divorced } \\
\text { Years of education }(n, \%) \\
\text { - } 0-5 \\
\text { - } 6-8 \\
\text { - } 9-13 \\
\text { - more than } 14\end{array}$ & $\begin{array}{c}90(77.0) \\
12(10.2) \\
9(7.7) \\
6(5.1) \\
55(47.1) \\
37(31.5) \\
23(19.7) \\
2(1.7)\end{array}$ \\
\hline $\begin{array}{l}\text { Work status }(n, \%) \\
\text { - employed } \\
\text { - retiredldisabled } \\
\text { - housewife } \\
\text { - unemployed } \\
\text { - student }\end{array}$ & $\begin{aligned} 24 & (20.4) \\
87 & (74.4) \\
1 & (0.9) \\
1 & (0.9) \\
4 & (3.4)\end{aligned}$ \\
\hline $\begin{array}{l}\text { CHD clinical history }(n, \%) \\
\text { - AMI } \\
\text { - Angioplasty } \\
\text { - Revascularization } \\
\text { - Valvulopathy } \\
\text { - CPOA } \\
\text { - Angina } \\
\text { - Hypertensive } \\
\text { - Diabetes }(n, \%)\end{array}$ & $\begin{array}{l}65(61.3) \\
39(36.8) \\
56(52.8) \\
14(13.2) \\
11(10.4) \\
45(42.5) \\
52(49.1) \\
22(20.8)\end{array}$ \\
\hline Smoking habit & $11(9.0)$ \\
\hline $\begin{array}{l}\text { Previous cardiovascular risk } \\
\text { - Cigarettes smoked } \\
\text { - Hypertension } \\
\text { - Dyslipidemia } \\
\text { - Familiarity }\end{array}$ & $\begin{array}{l}66(62.3) \\
65(60.7) \\
57(53.8) \\
61(57.5)\end{array}$ \\
\hline
\end{tabular}

Table 2. - Clinical data baseline and follow-up

\begin{tabular}{|c|c|c|c|c|c|}
\hline \multirow{2}{*}{$\frac{\text { Variables (mean } \pm \text { SD, range) } \mathbf{n}=\mathbf{1 1 7}}{\text { Years of illness }}$} & \multicolumn{2}{|c|}{ Baseline } & \multicolumn{2}{|c|}{ Follow-up } & \multirow{2}{*}{$\begin{array}{l}\mathbf{p} \\
-\end{array}$} \\
\hline & $5.2(5.4)$ & $1-19$ & - & - & \\
\hline Glycaemia & $109(39)$ & $75-337$ & $157(27)$ & $127-211$ & ns \\
\hline Total cholesterol & $188(41)$ & $103-296$ & $172(32)$ & $104-276$ & .0001 \\
\hline LDL cholesterol & $120(37)$ & $60-220$ & $111(29)$ & $60-209$ & .006 \\
\hline BMI & $27(3.7)$ & $20-38$ & $27(3.7)$ & $20-37$ & ns \\
\hline Variables $($ mean $\pm S D$, range $) n=35$ & \multicolumn{2}{|c|}{ Baseline } & \multicolumn{2}{|c|}{ Follow-up } & $\mathbf{p}$ \\
\hline Total cholesterol & \multicolumn{2}{|c|}{$200(51)$} & \multicolumn{2}{|c|}{$165(36)$} & .0001 \\
\hline LDL cholesterol & \multicolumn{2}{|c|}{$133(45)$} & \multicolumn{2}{|c|}{$107(33)$} & .002 \\
\hline
\end{tabular}


Table 3. - ASIHD: item response frequencies grouped in three sub-classifications. Baseline and follow-up data in the whole group $(n=117)$ are reported.

\begin{tabular}{|c|c|c|c|c|c|c|}
\hline $\mathbf{n}=\mathbf{1 1 7}$ & $\begin{array}{l}\text { Not at all/ } \\
\text { A little }\end{array}$ & Enough & $\begin{array}{l}\text { Much/ } \\
\text { Very much }\end{array}$ & $\begin{array}{l}\text { Not at all/ } \\
\text { A little }\end{array}$ & Enough & $\begin{array}{c}\text { Much/ } \\
\text { Very much }\end{array}$ \\
\hline Cognitive-Relational Antecedents & \multicolumn{3}{|c|}{ Baseline $\mathrm{n}(\%)$} & \multicolumn{3}{|c|}{ Follow-up n (\%) } \\
\hline Disease acceptance & $7(6.0)$ & $22(18.8)$ & $88(75.2)$ & $6(5.1)$ & $22(18.8)$ & $89(76.1)$ \\
\hline Disease limitations acceptance & $21(18.0)$ & $67(57.3)$ & $29(24.7)$ & $16(13.6)$ & $70(59.9)$ & $31(26.5)$ \\
\hline Disease knowledge & $28(23.9)$ & $57(48.8)$ & $32(27.3)$ & $28(24.0)$ & $66(56.4)$ & $23(19.6)$ \\
\hline Treatment utility in disease management & $2(1.8)$ & $44(37.6)$ & $71(60.6)$ & $3(2.6)$ & $51(43.6)$ & $63(53.8)$ \\
\hline Treatment utility in QoL improvement & $9(7.6)$ & $56(47.9)$ & $52(44.5)$ & $11(9.4)$ & $58(49.5)$ & $48(41.1)$ \\
\hline $\begin{array}{l}\text { Perceived family/social support in } \\
\text { disease management }\end{array}$ & $8(6.9)$ & $34(29.1)$ & $75(64.0)$ & $9(7.6)$ & $29(24.8)$ & $39(67.6)$ \\
\hline \multicolumn{7}{|l|}{$\begin{array}{l}\text { Self-efficacy in behavioural adherence } \\
\text { and stress management } \\
\text { To be able to: / been able to: }\end{array}$} \\
\hline take medicines punctually & $3(2.6)$ & $25(21.4)$ & $89(76.0)$ & $4(3.5)$ & $25(21.4)$ & $88(75.1)$ \\
\hline follow dietary prescriptions & $29(24.8)$ & $53(45.3)$ & $35(29.9)$ & $21(18.0)$ & $58(49.5)$ & $38(32.5)$ \\
\hline avoid smoking & $10(8.5)$ & $3(2.6)$ & $104(88.9)$ & $10(8.5)$ & $4(3.5)$ & 103(88.0) \\
\hline consume alcohol moderately & $3(2.6)$ & $9(7.7)$ & $105(89.7)$ & $1(0.9)$ & $13(11.1)$ & $103(88.0)$ \\
\hline exercise following medical advice & $21(18.0)$ & $51(43.6)$ & $45(38.4)$ & $28(24.0)$ & $40(34.3)$ & 49 (41.7) \\
\hline $\begin{array}{l}\text { identify physical/psychological } \\
\text { fatigue signs }\end{array}$ & $16(13.7)$ & $58(49.5)$ & $43(36.8)$ & $13(11.1)$ & $69(59.0)$ & 35 (29.9) \\
\hline reduce stress sources & $38(32.5)$ & $46(39.3)$ & $33(28.2)$ & $16(13.7)$ & $63(53.8)$ & $38(32.5)$ \\
\hline manage stressful situations & $27(23.0)$ & $55(47.1)$ & $35(29.9)$ & $10(8.5)$ & $71(60.7)$ & $36(30.8)$ \\
\hline monitor clinical parameters & $13(11.1)$ & $41(35.0)$ & $63(53.9)$ & $10(8.5)$ & $38(32.5)$ & $69(59.0)$ \\
\hline
\end{tabular}

Table 4. - ASIHD: statistically significant item response frequencies of the psychologically treated subgroup ( $n=35$ ) (baseline vs follow-up).

\begin{tabular}{|c|c|c|c|c|c|c|}
\hline & $\begin{array}{l}\text { Not at all/ } \\
\text { A little }\end{array}$ & Enough & $\begin{array}{l}\text { Much/ } \\
\text { Very much }\end{array}$ & $\begin{array}{l}\text { Not at all/ } \\
\text { A little }\end{array}$ & Enough & $\begin{array}{c}\text { Much/ } \\
\text { Very much }\end{array}$ \\
\hline $\mathrm{n}=35$ & $\begin{array}{l}\text { Baseline } \\
\mathrm{n}(\%)\end{array}$ & & & $\begin{array}{l}\text { Follow-up } \\
\text { n (\%) }\end{array}$ & & \\
\hline \multicolumn{7}{|l|}{ Cognitive-Relational antecedents } \\
\hline Disease limitations acceptance $*$ & $12(34.3)$ & $22(62.9)$ & $1(2.9)$ & $6(17.1)$ & $22(62.9)$ & $7(20.0)$ \\
\hline \multicolumn{7}{|l|}{$\begin{array}{l}\text { Self-efficacy in behavioural adherence } \\
\text { and stress management }\end{array}$} \\
\hline $\begin{array}{l}\text { To be able to: / been able to: } \\
\text { follow dietary prescriptions * }\end{array}$ & $13(37.1)$ & $15(42.9)$ & $7(20.0)$ & $7(20.0)$ & $17(48.6)$ & $11(31.4)$ \\
\hline
\end{tabular}

* Wilcoxon Test: Baseline vs Follow-up, p=.01

lowing points 4-6 and are depicted in Figure 1.

4. Among socio-demographic variables, only age resulted to be significantly correlated to ASHID self-efficacy in taking medicines punctually ( $\mathrm{r}=-$ $.25, \mathrm{p}=.008$ ) (Fig. 1). As to the comparisons of ASHID baseline scores divided into groups according to socio-demographic variables, only one resulted statistically significant: perceived family/social support in disease management and family status (Kruskal-Wallis test, $\mathrm{p}=.001$ ) (Fig. 2).

5. No significant correlations between age and years of illness and AD percentile scores emerged. No statistically significant differences emerged for AD percentile baseline scores divided into groups according to socio-demographic variables.

6. Among ASIHD baseline single item scores, many statistically significant correlations emerged (Fig. 1):

Disease acceptance showed significant positive correlations with management of stressful situations $(\mathrm{r}=.24, \mathrm{p}=.009)$.

Disease limitations acceptance showed significant positive correlations with disease knowledge $(\mathrm{r}=.34, \mathrm{p}=.0001)$, family/friend support $(\mathrm{r}=.27$, 


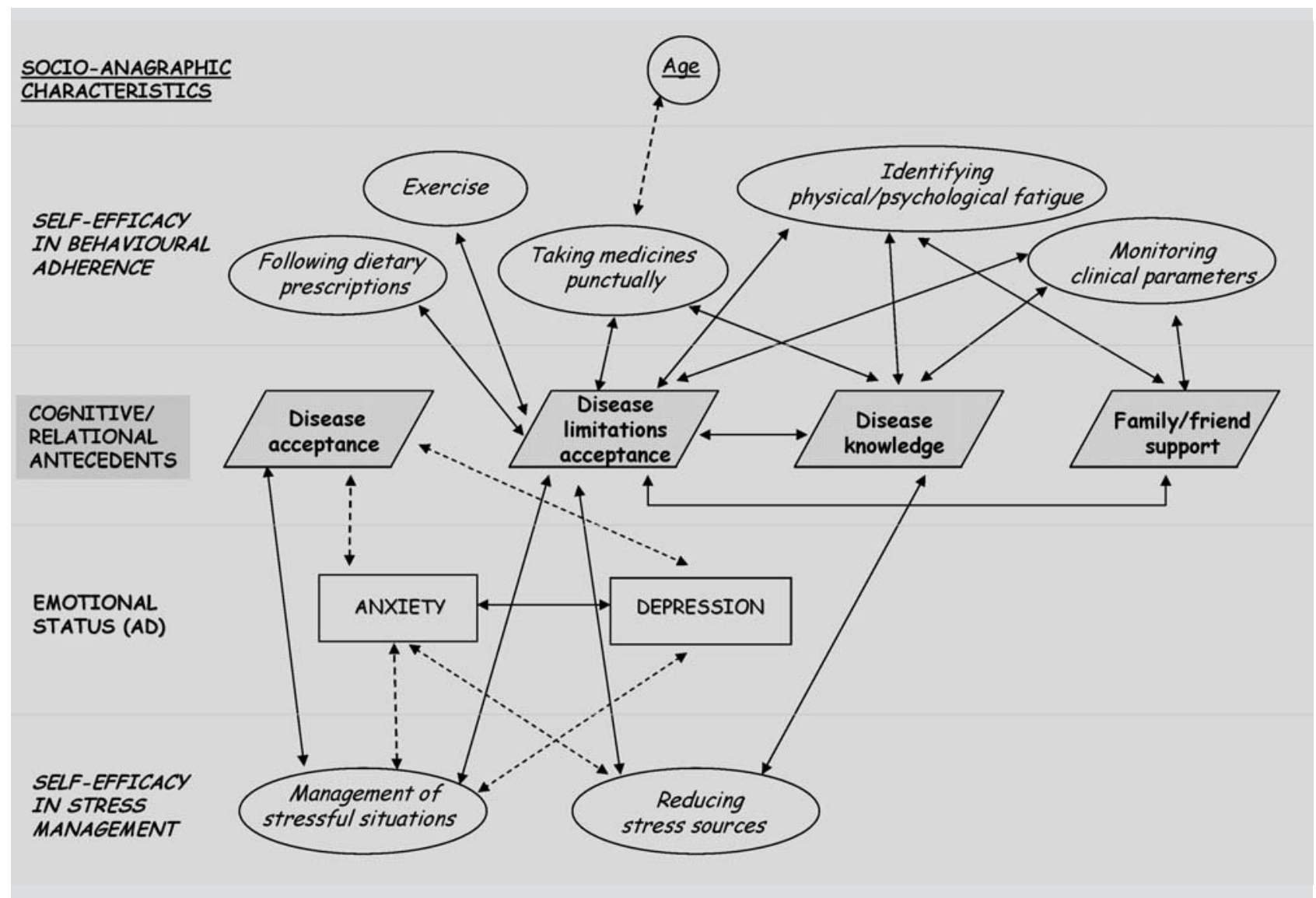

Figure 1. - Statistically significant correlations among ASHID, AD and socio-demographic data $(n=117 ; \mathrm{p} \leq 0.01)$.

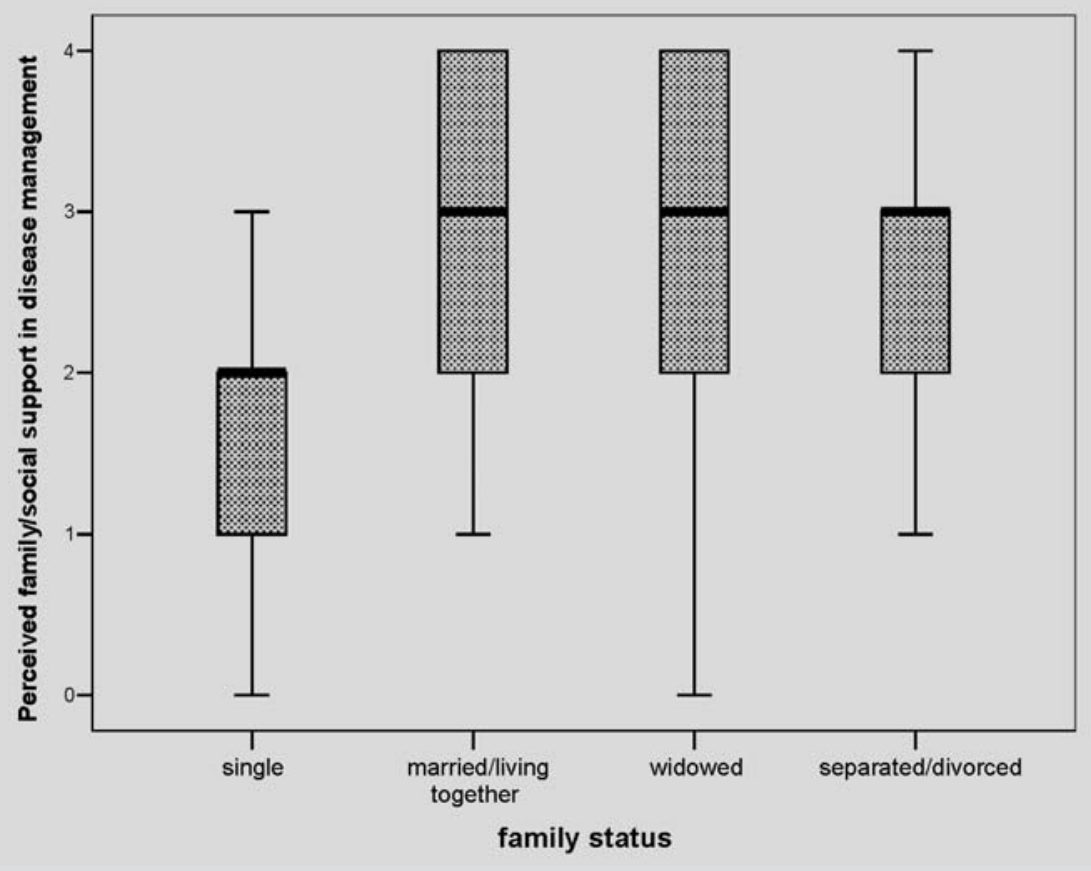

Figure 2. - Family/social support perceived in disease management.

$\mathrm{p}=.003)$, following dietary prescriptions $(\mathrm{r}=.38$, $\mathrm{p}=.0001)$, exercise $(\mathrm{r}=.35, \mathrm{p}=.0001)$, taking medicines punctually $(\mathrm{r}=.35, \mathrm{p}=.0001)$, identifying physical/psychological fatigue $(\mathrm{r}=.45, \mathrm{p}=.0001)$, monitoring clinical parameters $(\mathrm{r}=.42, \mathrm{p}=.0001)$, management of stressful situations $(\mathrm{r}=.26, \mathrm{p}=.006)$, and re- ducing stress sources $(\mathrm{r}=.34, \mathrm{p}=.0001)$.

Disease knowledge showed significant positive correlations with: taking medicines punctually $(\mathrm{r}=.46$, $\mathrm{p}=.0001$ ), identifying physical/psychological fatigue $(\mathrm{r}=.34, \mathrm{p}=.0001)$, monitoring clinical parameters $(\mathrm{r}=.31$, $\mathrm{p}=.001)$ and reducing stress sources $(\mathrm{r}=.24, \mathrm{p}=.01)$;

The family/friend support showed significant positive correlations with taking medicines punctually $(\mathrm{r}=.29, \mathrm{p}=.002)$ and monitoring clinical parameters $(\mathrm{r}=.36, \mathrm{p}=.0001)$.

Smoking and alcohol consumption did not correlate with any of the cognitive relational antecedents above listed.

Concerning the correlations between $\mathrm{AD}$ percentile scores and ASIHD scores, anxiety showed significant negative correlations with disease acceptance $(\mathrm{r}=-.27, \mathrm{p}=.004)$, reducing stress sources $(\mathrm{r}=-.33, \mathrm{p}=.0001)$ and management of stressful situations $(\mathrm{r}=-.37, \mathrm{p}=.0001)$. Finally, depression showed significant negative correlations with disease acceptance $(r=-.26, p=.004)$ and with management of stressful situations $(\mathrm{r}=-.30, \mathrm{p}=.001)($ Fig. 1). 


\section{Discussion}

Some considerations stem from the pathway resulted from our data. More precisely, the pathway (depicted in Fig.1) shows that in the area of cognitive and relational antecedents, accepting the disease limitations plays a central role. This is the only topic that correlates with almost all the behaviours of disease management considered in our study: following dietary prescriptions, drugs assumption, physical exercise, identification of the signs of fatigue, monitoring the clinical parameters and stress management.

According to the Taylor's cognitive adaptation theory [32], the process through which patients adjust to the disease can be divided into three essential phases: Finding a meaning, attempting to control the course of the illness and its impact on life, trying to protect self-esteem by the comparison with others. This study confirms such a model, and extends it by identifying the connections between the disease knowledge, the acceptance of disease limitations, the perceived social and familiar support with the behaviours which constitute the concrete management of health.

State anxiety and depression in our pathway are related only to one cognitive/relational antecedents: disease acceptance, which can be understood as a change of label (coming out from the world of the healthy and entering the irreversible world of the unhealthy).

It is interesting to notice that the acceptance of the disease limitations resulted not connected with the acceptance of the disease itself. These two topics belong to different psychological areas, the first meaning a set of abilities and the latter a need closer to the state of being rather than doing. Coherently, the connection emerged among the acceptance of disease limitations, the disease knowledge (controlling by learning) and the perceived familiar support (controlling by receiving help) confirms the dominance of "doing" in behavioural adherence independently of "being" (disease acceptance).

As to the baseline ASHID scores of the whole sample, the percentage of answers in Table 3 shows that the majority of patients have high scores in disease acceptance whereas only a minority of them have high scores in disease limitations acceptance and in disease knowledge. This suggests that the conceptual and abstract acceptance of the disease might be easier than the acceptance of its concrete impact on daily life or than its detailed knowledge. As to self-efficacy in behavioural adherence and stress management, the percentage of answers shows that most patients report high self-efficacy in taking medicine punctually, avoiding smoking and controlling alcohol consume, but only a minority of them report high self-efficacy in following dietary prescriptions, doing exercise, identifying fatigue and reducing or managing stressful situations. These results suggest that giving up a risk behaviour (i.e. smoking) and to taking medicines may be psychologically less demanding than to adopting and maintaining healthy behavioural changes in daily life (i.e. diet, exercise). Intervention efforts should therefore focus on diet habits, exercise and stress, which are an important part of cardiac rehabilitation and secondary prevention, together with the pharmacological treatment.

Finally, among socio-anagraphic variables, only age turned out to be significantly connected to self-efficacy in taking medicine punctually: the older the patient, the lower the level of self efficacy in pharmacological adherence (Fig.1). Not surprisingly, among family status variable, a lower perceived family/social support in disease management is reported by single patients (Fig. 2). Work status, gender, educational level and years of illness did not show any correlation with anxiety and depression, cognitive relational antecedents, behavioural adherence self-efficacy and stress management self-efficacy.

At follow up, the percentage of answers to ASIHD scores remain substantially unchanged, as well as anxiety and depression scores, confirming the relatively stable nature, in a brief follow-up, of these behavioural and emotional variables. The isolated significant reduction of total and LDL cholesterol levels observed was probably due to the multidisciplinary approach (medical, psychological and nutritional) focused on diet and pharmacological treatment of dislipidemic disorders. As to follow up comparison data of the 35 psychologically treated patients, only two significant differences emerged: acceptance of disease limitations and self-efficacy in following dietary prescriptions. While confirming the importance of a multidisciplinary intervention enlight the specific usefullness of a psychological approach. Further studies are needed on wider samples.

The present results may have practical implications for the rehabilitation and counselling of CHD patients. We are in agreement with [33] that assessing patients' level of self-efficacy may provide a more accurate indication of adherence behaviour motivation. It may be therefore useful to implement specific interventions aimed at improving behaviour specific self-efficacy with eventual positive consequences on adherence and health status. Moreover, focusing on patients' cognitive representations of illness (cognitive/emotional antecedents) could favour the disease adjustment process as a part of the rehabilitation and training intervention [20]. The working model we propose focuses not only on the emotional aspects but above all on every day life operational and practical variables based on an intervention tailored to what has come out from the ASIHD schedule.

Some limitations can be enlighted. First of all, data should be considered with caution as regards reliance on self-report data; in fact there may be a discrepancy between self-reports and objective observations [34]. Secondly, the sample of patients considered in this study only included outpatients in a stable clinical condition. Therefore, our results can not be generalized to CHD patients with different clinical conditions than ours. Further studies with wider samples and more representative groups of CHD patients are needed. 


\section{Conclusions}

Our results support the importance of considering disease limitations acceptance as a central issue in CHD patient's illness adjustment. Our pathway, stemmed from the ASHID data, suggests that besides educational sessions, relaxation therapy, psychological treatment of anxiety and depression, a tailored cognitive-behavioural intervention might contribute to patient's illness management and adherence to every aspect of it. The ASHID can be therefore considered a useful synthesis schedule of psychological/behavioural variables regarding the self-efficacy perceived by the patient in disease management. This schedule can be easily shared with all the team members in order to work in synergy on common priorities that respect the point of view of the patient and the clinical-rehabilitation purposes.

\section{Riassunto}

Razionale. La scarsa aderenza alle prescrizioni è stata riconosciuta come uno dei più importanti problemi nella gestione delle malattie croniche. Solo pochi studi hanno cercato di identificare quali fattori possano essere considerati predittivi di bassa aderenza alle prescrizioni farmacologiche e non farmacologiche in pazienti con cardiopatia ischemica (CI). Gli scopi del nostro studio osservazionale-longitudinale sono stati quelli di valutare in pazienti con CI ricoverati nel Day Hospital cardiologico $i$ seguenti aspetti: conoscenza e accettazione di malattia riferita, autoefficacia percepita nella gestione della malattia e stato emotivo, nonché le eventuali relazioni tra queste variabili.

Materiale e metodi: I pazienti sono stati valutati durante i primi giorni di DH (basale) e alcuni giorni prima della dimissione (follow-up) attraverso l'Adherence Schedule in Ischemic Heart Disease (ASIHD) e la Scheda di Valutazione di Ansia e Depressione $(A D)$. L'ASIHD ̀̀ uno strumento finalizzato alla valutazione degli antecedenti cognitivi, relazionali e comportamentali dell'aderenza al trattamento in pazienti con CI. Il programma riabilitativo comprendeva: training fisico individualizzato, monitoraggio dell'alimentazione, valutazione psicologica e interventi psicoeducazionali, quando indicato. I dati clinici basali e di follow-up, $i$ punteggi dell'ASHID e dell'AD sono stati analizzati sia considerando il campione totale $(n=117)$ che il sottogruppo selezionato in base ai criteri clinici per il counselling psicologico $(n=35$, gruppo trattato $p s i$ cologicamente). Sono state calcolate le intracorrelazioni e le intercorrelazioni tra i punteggi ASHID, $A D$ e $i$ dati socio-demografici sui dati basali del campione totale.

Risultati: I nostri pazienti con CI (età 62.6士9.3) erano principalmente maschi, sposati e pensionati. In media avevano 5,2 anni di malattia, e solo il 9\% è risultato fumatore, mentre il $62 \%$ lo erano stati fumatori in passato. Al follow-up i livelli di colesterolo totale e LDL sono risultati significativamente ridotti. Tra i punteggi degli item basali dell'ASHID, sono emerse molte intracorrelazioni, in particolare: l'accettazione delle limitazioni legate alla malattia è risultata correlata positivamente e in modo significativo con: conoscenza di malattia ( $r=.34$, $p=.0001)$, supporto socio-familiare $(r=.27$, $p=.003)$, seguire indicazioni alimentari $(r=.38$, $p=.0001)$, svolgere attività fisica $(r=.35, p=.0001)$, assumere correttamente le medicine ( $r=.35$, $p=.0001)$, riconoscere segni di affaticamento fisico elo psicologico $(r=.45, p=.0001)$, registrare parametri clinici $(r=.42, p=.0001)$, gestire situazioni stressanti $(r=.26, p=.006)$, e ridurre fonti di stress $(r=.34, p=.0001)$.

Relativamente alle intercorrelazioni significative fra i punteggi AD e ASHID, l'accettazione di malattia è risultata correlare negativamente con ansia e depressione ( $r=-.27, p=.004 ; r=-.26, p=.004$ rispettivamente).

Conclusioni: Il pathway emerso dai nostri dati evidenzia che nell'area degli antecedenti cognitivi e relazionali dell'aderenza, l'accettazione delle limitazioni legate alla malattia può essere considerata un aspetto centrale nell'adattamento alla malattia e nell'aderenza alle prescrizioni da parte del paziente. Inoltre, la scheda ASHID è risultato essere uno strumento utile e sintetico per la valutazione delle variabili psicologiche e comportamentali dell'autoefficacia percepita nella gestione della malattia. Il suo uso può quindi facilitare un lavoro sinergico in team su priorità condivise che rispettino il punto di vista del paziente e le finalità clinico-riabilitative.

Parole chiave: cardiopatia ischemica, aderenza, autoefficacia, depressione, ansia.

Aknowledgments. We would like to thank all the colleagues of the Psychology Unit (in particular Valeria Torlaschi) and of the Cardiology Department of our Institute for their valuable collaboration.

\section{References}

1. Meichenbaum D, Turk DC. Facilitating treatment adherence. A practitioner's guidebook. New York: Plenum Press, 1987.

2. Myers LB, Midence K. Adherence to treatment in medical conditions. Amsterdam: Harwood Academic Publishers, 1998.

3. Majani G. Compliance, adesione, aderenza. I punti critici della relazione terapeutica. Milano: McGraw-Hill, 2001.

4. Kripalani S, Yao X, Haynes RB. Interventions to enhance medication adherence in chronic medical conditions: a systematic review. Arch Intern Med 2007; 167(6): 540-50.

5. Sabate, E., editor. Adherence to long-term therapies: evidence for action. Geneva: World Health Organization, 2003.

6. Haynes RB, McDonald H, Garg AX, Montague P. Interventions for helping patients to follow prescriptions for medications. Cochrane Database Syst Rev 2002; (2): CD000011.

7. Haynes RB, Ackloo E, Sahota N, McDonald HP, Yao X. Interventions for enhancing medication adherence (Review). Cochrane Database Syst Rev 2008; (4): CD000011.

8. Evangelista LS, Dracup K. A closer look at compliance research in heart failure patients in the last decade. Prog Cardiovasc Nurs 2000; 15 (3): 97-103.

9. Leventhal MJ, Riegel B, Carlson B, De Geest S. Negotiating compliance in heart failure: remaining issues and questions. Eur J Cardiovasc Nurs 2005; 4(4): 298-307. 
10. Kulkarni SP, Alexander KP, Lytle B, Heiss G, Peterson ED. Long-term adherence with cardiovascular drug regimens. Am Heart J 2006; 151(1): 185-91.

11. Munger MA, Van Tassell BW, LaFleur J. Medication nonadherence: an unrecognized cardiovascular risk factor. Med Gen Med 2007; 9(3): 58.

12. Choudhry NK, Winkelmayer WC. Medication adherence after myocardial infarction: a long way left to go. J Gen Intern Med 2008; 23(2): 216-8.

13. Rasmussen JN, Chong A, Alter DA. Relationship between adherence to evidence-based pharmacotherapy and longterm mortality after acute myocardial infarction. JAMA 2007; 297(2): 177-86.

14. Wei L, Fahey T, MacDonald TM. Adherence to statin or aspirin or both in patients with established cardiovascular disease: exploring healthy behaviour vs. drug effects and 10-year follow-up of outcome. Br J Clin Pharmacol 2008; 66(1): 110-6.

15. DiMatteo MR, Lepper HS, Croghan TW. Depression is a risk factor for noncompliance with medical treatment: meta-analysis of the effects of anxiety and depression on patient adherence. Arch Intern Med 2000; 160(14): 2101-7.

16. Gehi A, Haas D, Pipkin S, Whooley MA. Depression and medication adherence in outpatients with coronary heart disease: findings from the Heart and Soul Study. Arch Intern Med 2005; 165(21): 2508-13.

17. Sud A, Kline-Rogers EM, Eagle KA et al. Adherence to medications by patients after acute coronary syndromes. Ann Pharmacother 2005; 39(11): 1792-7.

18. Edwards R, Suresh R, Lynch S, Clarkson P, Stanley P. Illness perceptions and mood in chronic fatigue syndrome. J Psychosom Res 2001; 50(2): 65-8.

19. Jopson NM, Moss-Morris R. The role of illness severity and illness representations in adjusting to multiple sclerosis. J Psychosom Res 2003; 54(6): 503-11.

20. Aalto AM, Aro AR, Weinman J, Heijmans M, Manderbacka K, Elovainio M. Sociodemographic, disease status, and illness perceptions predictors of global self-ratings of health and quality of life among those with coronary heart disease-one year follow-up study. Qual Life Res 2006; 15(8): 1307-22.

21. Bandura A, Social Foundations of Thought and Action: A Social Cognitive Theory. Prentice-Hall, NJ: Englewood Cliffs, 1986.

22. Scholz U, Nagy G, Göhner W, Luszczynska A, Kliegel Matthias. Changes in self-regulatory cognitions as predictors of changes in smoking and nutrition behaviour. Psychology and Health 2009; 24(5): 545-561.
23. Anderson ES, Wojcik JR, Winett RA, Williams DM. Social-cognitive determinants of physical activity: the influence of social support, self-efficacy, outcome expectations, and self-regulation among participants in a churchbased health promotion study. Health Psychol 2006; 25(4): 510-20.

24. Johnson MJ. The Medication Adherence Model: a guide for assessing medication taking. Res Theory Nurs Pract 2002; 16(3): 179-92.

25. Majani G, Pierobon A, Giardini A, Callegari S. Valutare e favorire l'aderenza alle prescrizioni in riabilitazione cardiologica e pneumologica. Pavia: Maugeri Foundation Books, 2007.

26. Vedana L, Baiardi P, Sommaruga M, et al. Clinical validation of an anxiety and depression screening test for intensive in-hospital rehabilitation. Monaldi Arch Chest Dis 2002; 58(2): 101-6.

27. Sanavio E, Bertolotti G, Michielin P, Vidotto G, Zotti AM. CBA 2.0 Cognitive Behavioural Assessment 2.0. Firenze: Organizzazioni Speciali, 1997.

28. Fourth Joint Task Force of the European Society of Cardiology and other societies on cardiovascular disease prevention in clinical practice (constituted by representatives of nine societies and by invited experts). European guidelines on cardiovascular disease prevention in clinical practice: full text. Eur J Cardiovasc Prev Rehabil 2007; 14 Suppl 2: S1-113.

29. Baiardini I, Braido F, Giardini A et al. Adherence to treatment: assessment of an unmet need in asthma. $J$ Investig Allergol Clin Immunol 2006; 16(4): 218-23.

30. Dorz S, Novara C, Sica C, Sanavio E. Burnout syndrome among health workers caring for AIDS patients: predictive variables G Ital Med Lav Ergon 2004; 26(2): 114-8.

31. Tomasich A, Rossi Ferrario S, Guzzi L, Lascioli R, Passante K. L'autoefficacia percepita e la riabilitazione respiratoria. G Ital Med Lav Erg 2006; 28(1)Suppl Psic1: 29-33.

32. Taylor SE, Lobel M. Social comparison activity under threat: downward evaluation and upward contacts. Psychol Rev 1989; 96: 569-575.

33. Schweitzer RD, Head K, Dwyer JW. Psychological factors and treatment adherence behavior in patients with chronic heart failure. J Cardiovasc Nurs 2007; 22(1): 76-83.

34. Vik SA, Maxwell CJ, Hogan DB. Measurement, correlates, and health outcomes of medication adherence among seniors. Ann Pharmacother 2004; 38(2): 303-12. 